\title{
AUDITORIA DE PROCESSO DE ENFERMAGEM EM PRONTO ATENDIMENTO.
}

TORES: SILVANA MARIA VIEIRA SPESSOTTO, RENATO RISSATO TESIN, ANA CAROLINA FERREIRA FRANCISCO, CINTHIA LEITE DEIROZ, DÉBORA DE FÁTIMA DE SOUZA ROQUE.

\section{INTRODUÇÃO}

Auditoria é uma revisão das atividades, registros, transações e operações de uma instituição ou de um projeto, efetuada por auditores, com a finalidade de assegurar a fidelidade dos registros e proporcionar credibilidade dos relatórios apresentados à administração.

Pensando em sistema de saúde transformamos essa atividade em Auditoria de Processo de Enfermagem, onde em nosso serviço contamos enfermeiros que realizam toda a auditoria de $10 \%$ do atendimento total do mês dentro do Pronto Atendimento.

\section{OBJETIVO}

Avaliar as atividades desenvolvidas pela equipe de enfermagem desde a realização da Classificação de Risco até o clínico (Alta/internação/óbito/transferência).

\section{METODOLOGIA}

Foi desenvolvida uma planilha em Excel que é alimentada por todos os enfermeiros classificadores diariamente se baseando em $10 \%$ do número de atendimento do dia anterior, que ao final se obtém $10 \%$ do número do mês. Dentro desta auditoria é avaliado como o paciente é classificado no fluxograma e discriminador relacionando com o diagnóstico médico dado após avaliação do plantonista. Nos casos em que ocorrem divergências relacionadas à equipe de enfermagem é aberto ciclos de treinamento para atualização e sanado dúvidas relacionadas a este processo. Também são avaliados os tempos de espera estabelecidos através do Protocolo de Classificação de Risco que são avaliados também através de Indicadores de Qualidade em um Sistema de Gestão. São auditadas as solicitações de avaliação de especialistas, as anotações de enfermagem no prontuário do paciente avaliando o preenchimento correto do mesmo e do conteúdo descrito assegurando a veracidade das informações.

\section{MODELO DE IMPRESSO DE AUDITORIA DE PROCESSO MENSAL}

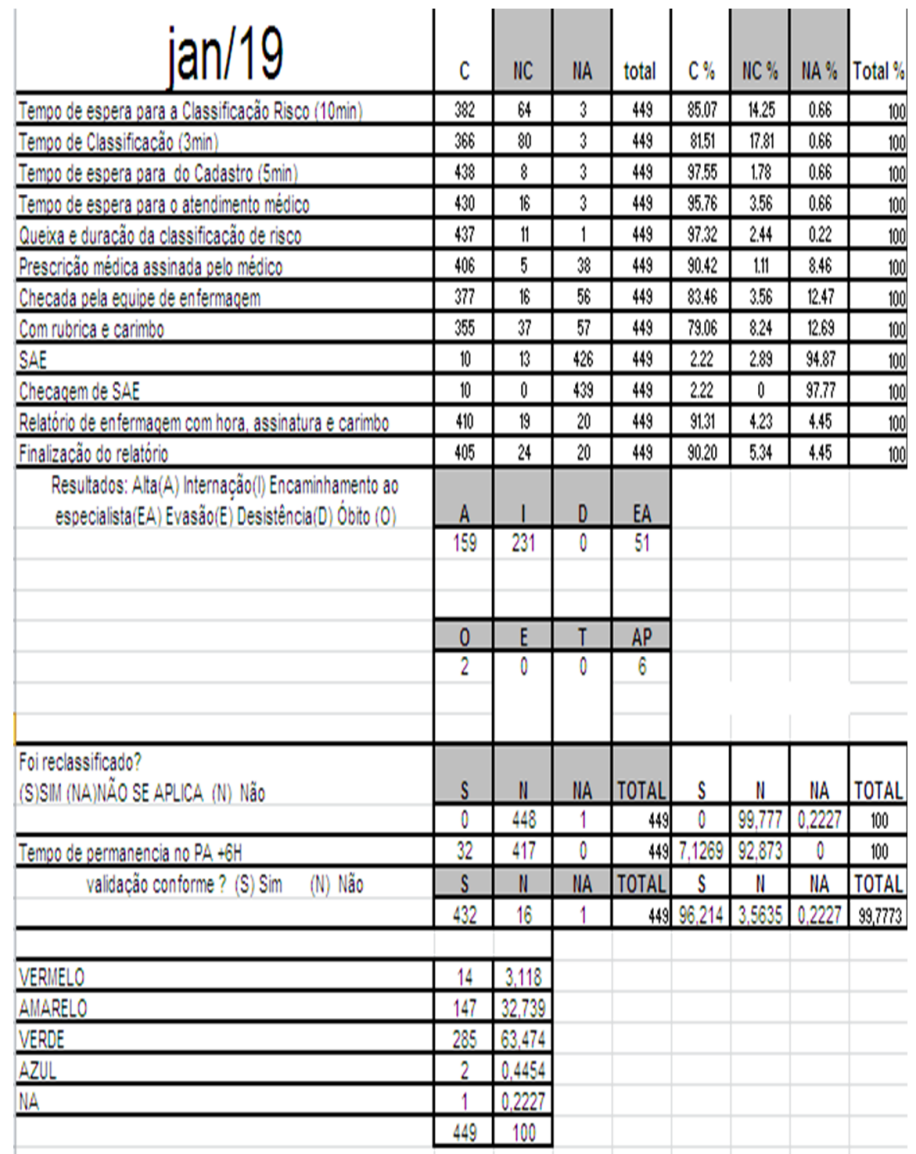

\section{CONCLUSÃO}

Esta atividade foi desenvolvida pensando em melhoria continua da assistência prestada aos nossos clientes, na segurança dos processos estabelecidos em nossa instituição e em desenvolver os colaboradores na realização dos processos praticados por eles e forma eficiente e segura, visando oferecer a melhor experiência em atendimento de urgência e emergência.

\section{REFERÊNCIAS}

Manual da ONA 20018 (Organização Nacional de Acreditação), NBR ISO 9001:2015; RESOLUÇÃO - RDC № 36, DE 25 DE JULHO DE 2013 - Segurança do paciente em serviços de saúde; RESOLUÇÃO CFM n 1.638/2002 - Obrigatoriedade das Comissões de Revisão de Prontuários em serviços de Saúde.

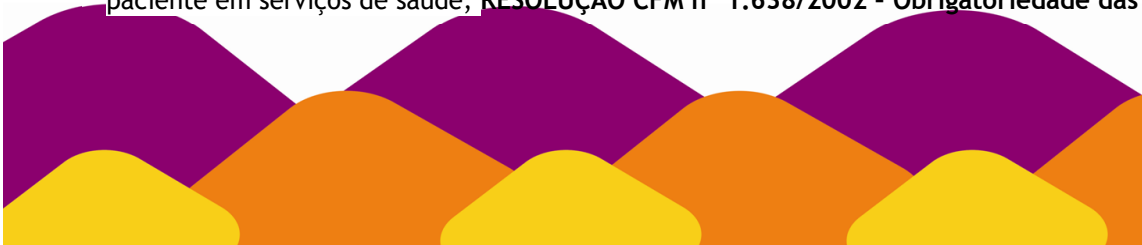

